Research Article

\title{
Prevalence of gastroesophageal reflux disorder in arrhythmic patients and adjunctive effects of proton pump inhibitors on comorbid atrial fibrillation
}

\author{
Keita Odashiro, Shioto Yasuda, Taku Yokoyama, Shunsuke Yoda, Hirotaka Noda, \\ Mitsuhiro Fukata, Takeshi Arita, Toru Maruyama*, Koichi Akashi
}

\begin{abstract}
Department of Medicine and Biosystemic Science, Kyushu University Graduate School of Medical Sciences, Fukuoka, Japan
\end{abstract}

Received: 20 June 2015 Accepted: 05 July 2015

\section{*Correspondence to: Dr. Toru Maruyama, Email: maruyama@artsci. kyushu-u.ac.jp}

Copyright: (C) the author(s), publisher and licensee Medip Academy. This is an open-access article distributed under the terms of the Creative Commons Attribution Non-Commercial License, which permits unrestricted non-commercial use, distribution, and reproduction in any medium, provided the original work is properly cited.

\begin{abstract}
Background: Although the coexistence of atrial fibrillation (AF) and gastroesophageal reflux disorder (GERD) has been reported, the prevalence of GERD in arrhythmic patients remains unknown. This study aimed to investigate the relationship between GERD and several kinds of arrhythmia, and the therapeutic effects of proton pump inhibitors (PPI) on AF.

Methods: In Study 1, patients with various kinds of arrhythmia ( $\mathrm{n}=147)$ including AF ( $\mathrm{n}=98)$ were administered a GERD-specific questionnaire (F-scale). In Study 2, patients with $\mathrm{AF}$ and GERD $(\mathrm{n}=27)$ responded to an AF-specific questionnaire (AFQLQ) before and after the additive PPI therapy to explore the effects of PPI on comorbid AF. In Study 3, device memory was assessed as it is related to PPI administration in pacemaker patients with GERD and AF $(n=5)$ to study the effects of PPI on device-documented AF.

Results: Left atrial (LA) size and F-scale scores in AF patients were the largest among the arrhythmic patients in Study 1. Logistic regression analysis showed no independent determinants of GERD. F-scale scores and AFQLQ scores showed temporal and partial correlations and significant improvement after starting PPI in Study 2. However, device interrogation confirmed limited AF improvement by starting PPI in Study 3.

Conclusions: GERD is prevalent in AF patients. LA size is not an independent determinant of GERD. Symptoms of AF were improved, whereas device-documented paroxysms of AF were not ameliorated by PPI administration. A large-scale prospective study is required to conclude the efficacy of PPI on the comorbid AF.
\end{abstract}

Keywords: Atrial fibrillation, Device interrogation, Gastroesophageal reflux disorder, Proton pump inhibitors, Questionnaire study

\section{INTRODUCTION}

Gastroesophageal reflux disorder (GERD) is a rapidly growing healthcare problem in developed countries due to modern lifestyle, the prevalence of obesity, ${ }^{1}$ sleep apnea ${ }^{2}$ and metabolic syndrome, ${ }^{3}$ rapid progression of aging, and reduced rate of Helicobacter pylori infection. ${ }^{4}$ The lower esophageal sphincter tends to relax in those with obesity, a full stomach, ${ }^{1,5}$ or sleep apnea, ${ }^{2}$ whereas hiatal hernias are prevalent in the elderly. ${ }^{6}$ Although GERD is sometimes associated with atrial fibrillation (AF), ${ }^{7-10}$ the prevalence of GERD in patients with various kinds of arrhythmia remains unknown.

AF is a common age-dependent arrhythmia, ${ }^{11}$ and new risk factors associated with it have emerged, i.e., sleep apnea ${ }^{12}$ and metabolic syndrome. ${ }^{13} \mathrm{AF}$ and GERD share the same predisposing factors, including metabolic syndrome, ${ }^{3,13}$ sleep apnea, ${ }^{2,12}$ and senescence. ${ }^{6,11}$ Although our recent work has focused on this relationship, ${ }^{14,15}$ the question remains whether this relationship is causal or coincidental. Therefore, the goal of this observational study was to investigate: (1) the prevalence of GERD in a variety of arrhythmic patients, (2) the alterations of symptoms before and after treatment with proton pump inhibitors (PPI) using disease-specific questionnaires in patients with GERD and concomitant $\mathrm{AF}$, and (3) the effects of PPI on the paroxysms of AF in pacemaker patients with GERD and AF.

\section{METHODS}

\section{Patient population}

This investigation was approved by the internal ethics committee (18038 and 24064, UMIN000009151) and 
conducted according to the Declaration of Helsinki (2008). Patients with various kinds of arrhythmia were enrolled in this study between September 2010 and March 2014, and were followed regularly at the outpatient clinic of Kyushu University Hospital. Written informed consent was obtained from all patients prior to their participation. Patients with malignancy, dementia, acute coronary syndrome, acute heart failure, and hemodialysis were excluded. All patients underwent standard electrocardiograms (ECG), echocardiography, and chest X-ray, and many received ambulatory or exercise ECG and chest computed tomography in their regular follow-up visits to the outpatient clinic.

\section{Study protocol}

This study was divided into three parts. Patients with various kinds of arrhythmia $(n=147)$ were enrolled in Study 1 . They were administered a questionnaire (frequency scale for symptoms of GERD, the so-called F-scale) in the regular follow-up visits. All arrhythmic patients were prescribed optimized antiarrhythmic agents and/or anticoagulants. The F-scale was used to screen the arrhythmic patients with GERD, and determinants of GERD were analyzed by uniand multi-variate analyses using baseline characteristics.

The patients with AF and GERD diagnosed using the F-scale $(n=27)$ were enrolled in Study 2. The classification of types (paroxysmal, persistent, or permanent) of AF, definition of non-valvular AF, and indication of anticoagulation with warfarin or novel oral anticoagulants were based on the guideline of the European Society of Cardiology, ${ }^{16}$ although persistent AF was difficult to distinguish from paroxysmal $\mathrm{AF}$ in the monthly follow-up visits. PPI (rabeprazole, lansoprazole, and esomeprazole) were administered to these patients, whereas prescriptions other than PPI were not altered. The choice of PPI was based on the discretion of treating physicians. Patients responded to the AF-specific questionnaire of AF quality of life questionnaire (AFQLQ) in addition to the F-scale. These questionnaires were completed before and 3 months after starting the administration of PPI.

In Study 3, the patients with pacemaker implantation were screened among those enrolled in Study 2. PPI administration was continued at least to 6 months. Permanent dual-chamber pacemakers programmed to DDD have dedicated functions of AF detection and electrogram storage. Regular checkups of pacemakers were conducted every 6 months in our outpatient clinic, and these patients underwent pacemaker interrogation before and 6 months after starting PPI administration. A questionnaire survey was conducted before and 3 and 6 months after starting PPI in the pacemaker patients. Device follow-up included checking the battery longevity, pacemaker mode and function, lead impedance, atrial and ventricular pacing threshold, and voltages of patients' own $\mathrm{P}$ and $\mathrm{R}$ waves. AF occurring during the interval of regular check-ups was considered as automated mode switch observed in the absence of atrial overdrive pacing program. Mode switch rate was set to 200 pacing per mins, and the stored bipolar atrial electrograms were reviewed blindly by cardiac device representatives. The number, the maximum duration, and the total duration of paroxysms of AF were investigated.

\section{Questionnaire study}

The F-scale is a widely used questionnaire designed specifically to screen for GERD. ${ }^{17}$ It covers the 12 most common GERD symptoms. The symptoms were scored based on their frequency as follows: never $=0$, occasionally $=1$, sometimes $=2$, often $=3$, or always $=4$. Therefore, the total score of the F-scale reflects the presence of GERD-related symptoms semi-quantitatively. This questionnaire is composed of two parts: 7 items relating to reflux-like symptoms and 5 items relating to dysmotilitylike dyspeptic symptoms. Total scores and those relating to reflux and dyspeptic symptoms were analyzed separately. The cutoff value for the total score to diagnose symptomatic GERD was set at 8 points, which has been reported to yield a sensitivity of $62 \%$, specificity of $59 \%$, and diagnostic accuracy of $60 \%$ as a reference for endoscopy. ${ }^{17}$

AFQLQ is a questionnaire formulated specifically for AF patients to assess the quality of life (QOL) related strictly to the symptoms of AF. This questionnaire consists of 3 subscales: AF1 assesses the subjective frequency and duration of AF symptoms (6 items, 0-24 points), AF2 assesses the severity of AF symptoms ( 6 items, $0-18$ points), and AF3 assesses the limitations in daily life and other activities, and mental anxiety related to AF (14 items, 0-56 points). Higher scores indicate a more favorable QOL for each subscale and the validity of this AF-specific questionnaire was reported. ${ }^{18,19}$

The two kinds of questionnaire were self-administered by the patients at the regular follow-up visits after obtaining informed consent, and forwarded to the laboratory where data were analyzed by cardiologists who were unaware of the study protocol.

\section{Statistical analysis}

Continuous data are expressed as the mean \pm standard deviation, and discrete variables are indicated as numbers and percentages. In the questionnaire analysis, the F-scale scores were evaluated separately from highly ( $>8$ points) rated scores, that is, the incidence of GERD. The data distribution was examined using the Kolmogorov-Smirnov test for normality. Intergroup differences were compared by one-way Analysis of Variance for multiple comparisons of normally distributed data, or by the Kruskal-Wallis test for the other data. For paired data, differences were compared using Wilcoxon's sign rank test for data which did not show normality. Spearman's correlation was used to analyze the relationship between F-scale and AFQLQ scores, which were 
not distributed normally. Discrete variables were analyzed as a cross table using Fisher's exact test or Pearson's $\chi^{2}$ test with Yate's continuity correction, if necessary.

This questionnaire survey did not anticipate dropout cases, and hence the sample size was chosen to provide $90 \%$ power with an $\alpha$ error of 0.05 on two-sided comparison based on our preliminary questionnaire survey, ${ }^{14}$ and should have included $\geq 140$ cases in total. As logistic regression analysis, baseline characteristics were incorporated into univariate analysis, and variables showing significance were incorporated into multivariate analysis, which was performed using stepwise discrimination to detect independent contributors to GERD. Practical computation was performed using the Predictive Analytics Software (PASW) 18.0 version for Windows package (SPSS Inc., IBM, Chicago, IL, USA). A difference with a two-sided $\mathrm{p}<0.050$ was considered to indicate significance.

\section{RESULTS}

Normally distributed data included those on the age, body mass index, and echocardiography of subjects, whereas the distribution of $\mathrm{CHADS}_{2}$ scores, questionnaires (F-scale and AFQLQ) scores, and all data extracted from device memory did not show normality.

\section{Study 1}

Table 1 summarizes the baseline characteristics of the enrolled patients with various kinds of arrhythmia ( $n=147)$. Paroxysmal supraventricular tachycardia (PSVT) includes paroxysms of atrial tachycardia, atrioventricular nodal reentrant tachycardia, and atrioventricular reciprocating tachycardia based on accessory pathway syndrome. Patients with PSVT $(n=24)$ were younger than those with other types of arrhythmia $(\mathrm{p}<0.001)$. All patients with valvular AF $(\mathrm{n}=9)$ belonged to the group of permanent AF $(n=17)$, whereas those with non-valvular AF $(n=89)$ were divided into two AF groups (paroxysmal/persistent and permanent).

In echocardiography, left atrial (LA) diameter (LAD) and LA volume index (LAVI) showed significant differences, i.e., these indices in patients with permanent AF were larger than those in the other arrhythmic patients $(p<0.001)$. Left ventricular ejection fraction (LVEF) showed intergroup difference as well $(\mathrm{p}=0.002)$. F-scale scores also showed significant intergroup differences: the reflux score $(\mathrm{p}=0.046)$, dysmotility score $(p=0.043)$, and total score $(p=0.039)$ were the highest in patients with permanent $\mathrm{AF}$, and so the incidence of GERD was higher in AF patients than in the other arrhythmic patients $(\mathrm{p}<0.001)$. However, multivariate logistic regression analysis demonstrated no independent determinants of GERD, i.e. the type of arrhythmia alone tended to remain as a marginal contributor to GERD ( $\mathrm{p} \geq 0.054$ ), indicating again the significance of AF.

Study 1 consequently screened patients with paroxysmal or persistent AF and coexistent GERD $(n=27)$. The $\mathrm{CHADS}_{2}$ score and age of the 27 patients did not differ from those of the remaining patients with paroxysmal/ persistent AF, but without GERD $(n=54)$. Significant echocardiographic differences between the two groups were found in LAD (45.9 \pm 5.1 vs. $37.3 \pm 4.0 \mathrm{~mm}, \mathrm{p}<0.001)$ and LAVI (43.1 \pm 7.9 vs. $\left.35.7 \pm 9.8 \mathrm{ml} / \mathrm{m}^{2}, \mathrm{p}=0.011\right)$, but not in LVEF (67.7 \pm 8.1 vs. $68.3 \pm 7.4 \%, \mathrm{p}=0.846)$, implying LA size relating to symptomatic GERD (Table 1).

Table 1: Baseline characteristics of enrolled patients with various kinds of arrhythmia.

\begin{tabular}{|c|c|c|c|c|c|c|}
\hline$(\mathbf{N})$ & AFL (11) & $\begin{array}{l}\text { Permanent } \\
\text { AF (17) }\end{array}$ & $\begin{array}{c}\text { Paroxysmal or } \\
\text { persistent AF (81) }\end{array}$ & $\begin{array}{l}\text { PSVT } \\
(24)\end{array}$ & $\begin{array}{c}\text { Ventricular } \\
\text { Arrhythmias (14) }\end{array}$ & p value \\
\hline Age (y.o.) & $62.9 \pm 9.7$ & $65.1 \pm 11.0$ & $66.3 \pm 10.7$ & $48.8 \pm 18.0$ & $57.1 \pm 17.1$ & $<0.001$ \\
\hline Gender (M/F) & $7 / 4$ & $11 / 6$ & $54 / 27$ & $7 / 17$ & $9 / 5$ & 0.017 \\
\hline BMI $\left(\mathrm{kg} / \mathrm{m}^{2}\right)$ & $19.5 \pm 1.2$ & $19.5 \pm 1.6$ & $19.2 \pm 1.3$ & $19.0 \pm 1.0$ & $19.3 \pm 1.1$ & 0.704 \\
\hline LAD (mm) & $43.8 \pm 5.4$ & $45.9 \pm 8.0$ & $39.9 \pm 5.8$ & $32.3 \pm 5.8$ & $35.1 \pm 7.8$ & $<0.001$ \\
\hline LAVI (ml/m²) & $42.5 \pm 14.4$ & $52.9 \pm 16.6$ & $37.3 \pm 12.2$ & $34.0 \pm 18.5$ & $29.5 \pm 8.0$ & $<0.001$ \\
\hline LVEF (\%) & $61.8 \pm 14.5$ & $63.7 \pm 6.2$ & $68.1 \pm 7.5$ & $70.4 \pm 4.1$ & $61.2 \pm 9.4$ & 0.002 \\
\hline \multicolumn{7}{|l|}{ F-scale scores } \\
\hline Reflux & $1(0-10)$ & $2(0-8)$ & $1(0-24)$ & $0.5(0-8)$ & $0.5(0-4)$ & 0.046 \\
\hline Dysmotility & $2(0-10)$ & $2(0-8)$ & $1(0-18)$ & $0(0-5)$ & $0(0-4)$ & 0.043 \\
\hline Total & $4(0-20)$ & $6(0-10)$ & $2(0-42)$ & $1(0-13)$ & $1(0-8)$ & 0.039 \\
\hline GERD (\%) & $1(9.0)$ & $5(29.4)$ & $27(33.3)$ & $2(8.3)$ & $1(7.1)$ & $<0.001$ \\
\hline $\begin{array}{l}\text { Pacemaker } \\
\text { implantation (n) }\end{array}$ & 0 & 2 & 5 & 0 & 0 & - \\
\hline
\end{tabular}

Numbers in each column indicate the mean \pm SD for normally distributed data, median (left), and range (right, in parenthesis) of data which did not show normality, or the number, ratio, and percentage (parenthesis) of discrete variables ( $\mathrm{n}=147)$. AF: Atrial fibrillation; AFL: Atrial flutter, GERD: Gastroesophageal reflux disease, LAD: Left atrial dimension, LAVI: Left atrial volume index, LVEF: Left ventricular ejection fraction, PSVT: Paroxysmal supraventricular tachycardia, SD: Standard deviation 


\section{Study 2}

Table 2 summarizes the scores of the F-scale and AFQLQ before and 3 months after starting the administration of PPI ( $n=12$ for rabeprazole, $n=7$ for lansoprazole, and $n=8$ for esomeprazole) in patients with GERD associated with paroxysmal or persistent AF $(n=27)$. Concerning F-scale scores, total $(\mathrm{p}<0.001)$, reflux $(\mathrm{p}<0.001)$, and dysmotility $(p=0.013)$ scores were significantly reduced by starting the administration of PPI. With respect to AFQLQ, scores of AF1 $(\mathrm{P}=0.001)$ and AF2 $(\mathrm{p}<0.001)$, but not AF3 $(\mathrm{p}=0.491)$ were significantly increased by PPI administration. These questionnaires indicate a subjective improvement of not only symptomatic GERD but partially AF-related QOL after starting PPI therapy in patients with concurrent GERD and AF.

Correlations of the F-scale and AFQLQ were demonstrated individually before (Table 3 ) and 3 months after starting PPI (Table 4). Prior to PPI administration, reflex scores were significantly correlated with AF1 $(p=0.009)$, AF2 $(\mathrm{p}=0.005)$, and AF3 $(\mathrm{p}=0.011)$ scores, and dysmotility and total scores were closely correlated with all AF scores $(\mathrm{p}<0.001) .3$ months after starting PPI administration, AF2 scores were not correlated with any F-scores, whereas AF1 $(\mathrm{p}=0.003-0.018)$ and AF3 $(\mathrm{p}=0.001-0.008)$ scores were significantly correlated with all F-scale scores (Tables 2-4).
Study 2 screened 5 patients with paroxysmal AF and GERD, who underwent permanent dual-chamber pacemaker implantation for bradyarrhythmia. These patients $(80.1 \pm 7.0$ y.o. $)$ were significantly $(\mathrm{p}=0.002)$ older than the remaining patients without pacemaker (63.2 \pm 8.8 y.o., $\mathrm{n}=22)$. The $\mathrm{CHADS}_{2}$ score in the pacemaker patients $(2,[1-3])$ was significantly $(p=0.010)$ higher than that in the remaining patients $(1,[0-3])$. With respect to the questionnaire scores, a part of AFQLQ scores in the pacemaker patients was greater than that in the remaining AF patients $(p=0.042$ for $A F 1$, $p=0.390$ for $A F 2$, and $p=0.039$ for AF3). On the other hand, a part of F-scale scores in these patients was lower than that in the remaining patients ( $p=0.040$ for reflux score, $p=0.485$ for dysmotility score, and $\mathrm{p}=0.284$ for total score) prior to PPI administration. These findings indicate that pacemaker patients in Study $2(\mathrm{n}=5)$ showed relatively mild symptoms of GERD and favorable AF-related QOL.

\section{Study 3}

Five patients with pacemaker implantation in Study 2 were enrolled in Study 3. The dual-chamber pacemaker was implanted for sick sinus syndrome in all 5 patients and was capable of AF detection. Paroxysms of AF were recognized by long-term (3.2-5.5 years) follow-up of these patients after the pacemaker implantation. Pacemaker memory

Table 2: Changes in questionnaire scores before and 3 months after starting the administration of PPI.

\begin{tabular}{|lcccccc|}
\hline Scores & $\begin{array}{c}\text { Reflux } \\
\text { scores }\end{array}$ & $\begin{array}{c}\text { Dysmotility } \\
\text { scores }\end{array}$ & $\begin{array}{c}\text { Total } \\
\text { scores }\end{array}$ & AF1 & AF2 & AF3 \\
\hline Preadministration of PPI & $5(3-24)$ & $6(0-18)$ & $10(8-42)$ & $16(4-21)$ & $13(5-16)$ & $44(32-50)$ \\
\hline Postadministration of PPI & $4(0-19)$ & $5(0-15)$ & $7(4-32)$ & $18(8-22)$ & $15(8-17)$ & $45(31-50)$ \\
\hline p value & $<0.001$ & 0.013 & $<0.001$ & 0.001 & $<0.001$ & 0.491 \\
\hline
\end{tabular}

Numbers of scores are expressed as the median (left) and range (right, in parenthesis) of data which did not show normality (n=27), PPI: Proton pump inhibitors, AF: Atrial fibrillation, AFQLQ: Atrial fibrillation quality of life questionnaire

Table 3: Correlations of F-scale and AFQLQ scores before starting the administration of PPI.

\begin{tabular}{|lcccccc|}
\hline Scores & Reflux scores & Dysmotility scores & Total scores & AF1 & AF2 & AF3 \\
\hline Reflux scores & 1.000 & 0.404 & 0.710 & -0.491 & -0.520 & -0.481 \\
\hline & - & 0.037 & $<0.001$ & 0.009 & 0.005 & 0.011 \\
\hline Dysmotility scores & 0.404 & 1.000 & 0.894 & -0.666 & -0.650 & -0.710 \\
\hline & 0.037 & - & $<0.001$ & $<0.001$ & $<0.001$ & $<0.001$ \\
\hline Total scores & 0.710 & 0.894 & 1.000 & -0.626 & -0.626 & -0.666 \\
\hline & $<0.001$ & $<0.001$ & - & $<0.001$ & $<0.001$ & $<0.001$ \\
\hline AF1 & -0.491 & -0.666 & -0.626 & 1.000 & 0.767 & 0.804 \\
\hline & 0.009 & $<0.001$ & $<0.001$ & - & $<0.001$ & $<0.001$ \\
\hline AF2 & -0.520 & -0.650 & -0.626 & 0.767 & 1.000 & 0.570 \\
\hline & 0.005 & $<0.001$ & $<0.001$ & $<0.001$ & - & 0.002 \\
\hline AF3 & -0.481 & -0.710 & -0.666 & 0.804 & 0.570 & 1.000 \\
\hline & 0.011 & $<0.001$ & $<0.001$ & $<0.001$ & 0.002 & - \\
\hline
\end{tabular}

Each column is expressed as the correlation coefficient (upper) and $\mathrm{p}$ value (lower) of two scores ( $\mathrm{n}=27$ ), PPI: Proton pump inhibitors, AF: Atrial fibrillation, AFQLQ: Atrial fibrillation quality of life questionnaire 
interrogation detected AF paroxysms irrespective of the symptoms. The PPI administered to these patients was esomeprazole. Table 5 summarizes the questionnaire survey and device memory interrogation in these patients $(n=5)$. With respect to the questionnaire scores, reflux $(p=0.041)$ and total $(p=0.042)$ scores but not the dysmotility score $(p=0.157)$ in the F-scale were improved, whereas none of the AFQLQ scores were improved in these patients $(\mathrm{p} \geq 0.063)$ on 6-month treatment with PPI. The same was true for 3-month treatment (not shown). Device interrogation confirmed no significant alterations concerning the number $(p=0.138)$ and the maximum duration $(\mathrm{p}=0.345)$ of $\mathrm{AF}$ paroxysms. The total duration of AF paroxysms was barely abbreviated by the 6-month PPI therapy ( $\mathrm{p}=0.043$ ) (Table 5).

\section{DISCUSSION}

The main findings of this study are threefold. First, patients with AF showed large LA and high F-scale scores, leading to an increased incidence of GERD among various arrhythmic patients (Table 1). Second, PPI administration to patients with AF and GERD significantly ameliorated both all the F-scale scores and most AFQLQ scores
(Table 2), which are mutually correlated (Tables 3 and 4). Third, device interrogation confirmed limited suppressions of AF paroxysms by PPI administered to the pacemaker patients with AF and GERD (Table 5). The first part of this study (Study 1) reconfirmed the association of AF and GERD reported in literature ${ }^{7-10}$ and our recent studies. ${ }^{14,15}$ We hypothesized that LA size plays the key role in this association, i.e., an enlarged LA compresses or irritates the lower esophagus, leading to reflux symptoms, because of anatomical proximity. However, the LA size was not a significant contributor but AF per se may be a marginal $(\mathrm{p} \geq 0.054)$ contributor to GERD. One reason may be that AF patients were heterogeneous in this study.

PPI is the first line therapy for patients with non-erosive reflux disease ${ }^{20}$ as well as GERD. ${ }^{21}$ Although controversy exists, ${ }^{22}$ the hypothesis of GERD being a risk factor for AF raises the possibility of PPI as adjunctive treatment for AF. ${ }^{8,9,23}$ In a part of this study (Study 2), symptoms of both AF and GERD were ameliorated after PPI administration based on disease-specific questionnaires (Table 2). The therapeutic efficacy of PPI on AF has been sporadically described in a case report and a pilot study. ${ }^{24,25}$ Diagnosis

Table 4: Correlations of F-scale and AFQLQ scores 3 months after starting the administration of PPI.

\begin{tabular}{|lcccccc|}
\hline Scores & Reflux scores & Dysmotility scores & Total scores & AF1 & AF2 & AF3 \\
\hline Reflux scores & 1.000 & 0.435 & 0.822 & -0.450 & -0.209 & -0.498 \\
\hline Dysmotility scores & - & 0.023 & $<0.001$ & 0.018 & 0.295 & 0.008 \\
\hline & 0.435 & 1.000 & 0.824 & -0.553 & -0.209 & -0.752 \\
\hline Total scores & 0.023 & - & $<0.001$ & 0.003 & 0.297 & $<0.001$ \\
\hline & 0.822 & 0.824 & 1.000 & -0.541 & -0.237 & -0.657 \\
\hline AF1 & $<0.001$ & $<0.001$ & - & 0.004 & 0.235 & $<0.001$ \\
\hline & -0.450 & -0.553 & -0.541 & 1.000 & 0.507 & 0.691 \\
\hline AF2 & 0.018 & 0.003 & 0.004 & - & 0.007 & $<0.001$ \\
\hline & -0.209 & -0.209 & -0.237 & 0.507 & 1.000 & 0.308 \\
\hline AF3 & 0.295 & 0.297 & 0.235 & 0.007 & - & 0.119 \\
\hline & -0.498 & -0.752 & -0.657 & 0.691 & 0.308 & 1.000 \\
\hline
\end{tabular}

Each column is expressed as the correlation coefficient (upper) and p value (lower) of two scores (n=27), PPI: Proton pump inhibitors, AF: Atrial fibrillation, AFQLQ: Atrial fibrillation quality of life questionnaire

Table 5: Alterations of questionnaire scores and pacemaker interrogation before and 6 months after starting the administration of PPI.

\begin{tabular}{|c|c|c|c|c|c|c|c|c|c|}
\hline Variables & $\begin{array}{l}\text { Reflux } \\
\text { scores }\end{array}$ & $\begin{array}{l}\text { Dysmotility } \\
\text { scores }\end{array}$ & $\begin{array}{l}\text { Total } \\
\text { scores }\end{array}$ & AF1 & AF2 & AF3 & $\begin{array}{c}\text { Number of } \\
\text { paroxysms } \\
\text { (n) }\end{array}$ & $\begin{array}{l}\text { Maximum } \\
\text { duration of } \\
\text { paroxysms } \\
\text { (min) }\end{array}$ & $\begin{array}{c}\text { Total } \\
\text { duration of } \\
\text { paroxysms } \\
\text { (min) }\end{array}$ \\
\hline $\begin{array}{l}\text { Preadministration } \\
\text { of PPI }\end{array}$ & 3 & & 11) & $19(15$ & $13(12$ & 48 & $\begin{array}{c}127 \\
(89-230)\end{array}$ & $\begin{array}{c}401 \\
(256-522)\end{array}$ & $\begin{array}{c}6322 \\
(5389-8021)\end{array}$ \\
\hline $\begin{array}{l}\text { Postadministration } \\
\text { of PPI }\end{array}$ & $2(1-4)$ & $5(3-6)$ & $7(6-8)$ & $18(17-22)$ & $15(13-16)$ & $47(40-50)$ & $\begin{array}{c}131 \\
(77-201)\end{array}$ & $\begin{array}{c}399 \\
(234-501)\end{array}$ & $\begin{array}{c}6251 \\
(5103-7596)\end{array}$ \\
\hline $\mathrm{p}$ value & 0.041 & 0.157 & 0.042 & 0.276 & 0.063 & 0.157 & 0.138 & 0.345 & 0.043 \\
\hline
\end{tabular}

Numbers in each column indicate the median (upper) and range (lower, in parenthesis) of data which did not show normality $(\mathrm{n}=5$ ), PPI: Proton pump inhibitors, AF: Atrial fibrillation 
of GERD is symptom-oriented, and rare paroxysms of AF are hard to be documented. Therefore, Gerson et al. conducted simultaneous esophageal $\mathrm{pH}$ and ambulatory ECG monitoring to study the causal link between AF and GERD. Based on the coincidence of acid reflux and arrhythmic events, they concluded that aggressive acid suppression therapy is effective for rhythm control in patients with AF and GERD. ${ }^{26}$ Temporal and partial correlations between the two scores were compatible with the results of their study (Tables 3 and 4).

Subclinical AF cannot be detected except for implantable monitoring device or pacemaker interrogation. ${ }^{27}$ The Study 3 demonstrated that PPI showed limited suppressive effects on the paroxysms of selected AF patients (Table 5). It may be premature to conclude the definitive effects of PPI on the device-documented AF due to the small number of patients $(n=5)$ and possible proarrhythmic action of PPI, making the conclusion of Study 3 weak..$^{28,29}$ Moreover, the patients in Study 3 are significantly ( $\mathrm{p}=0.002$ ) older than the remaining patients in Study 2. Patients in Study 3 showed less severe symptoms of GERD and more favorable AF-related QOL relative to the remaining patients prior to PPI administration. Therefore, pacemaker patients did not necessarily represent the total patients with AF and GERD in our study. Cuomo et al. reported that gastroesophageal reflux alters neurocardiac functions in two strictly different ways: it modulates power spectral analysis of heart rate variability toward either sympathetic or parasympathetic dominance. They demonstrated that esomeprazole is effective only in patients showing a clear link between esophageal acidification and arrhythmias. ${ }^{30}$ The results of Study 3 are not contradictory to their outcome in that PPI may be effective in a distinctive subset of AF patients.

\section{Limitations}

This investigation enrolled patients with various kinds of arrhythmia as a single-center study. Although our hospital is a tertiary referral hospital, patient enrollment likely contained statistical bias, and PPI selection was not randomized. Although we set pacemaker interrogation study capable of asymptomatic AF detection, the small study sample for device interrogation $(n=5)$ necessitates future investigations. The same was true in an endoscopic examination $(n=9)$ to detect reflux esophagitis based on GERD.

\section{CONCLUSION}

The AF patients showed a large LA and prevalent GERD among other arrhythmic patients, although LA size was not an independent contributor to the development of GERD. The therapeutic role of PPI to improve AF symptoms was suggested by an AF-specific questionnaire, but device interrogation confirmed limited suppressive effects of PPI on AF paroxysms in pacemaker patients. This questionnaire study with device interrogation reconfirmed the association between AF and GERD, and a large-scale prospective study is required to conclude the efficacy of PPI as adjunctive therapy in the presence of comorbid AF.

\section{ACKNOWLEDGMENTS}

We thank Ms. Miki Ando and Ms. Yuko Shibata for secretarial assistance. We also thank Dr. Akiko Chishaki (Department of Health Science, Kyushu University Graduate School of Medical Sciences) for skillful collaboration.

\section{Funding: No funding sources}

Conflict of interest: None declared

Ethical approval: This study was approved by the internal ethics committee (18038 and 24064, UMIN000009151)

\section{REFERENCES}

1. Friedenberg FK, Xanthopoulos M, Foster GD, Richter JE. The association between gastroesophageal reflux disease and obesity. Am J Gastroenterol. 2008;103(8):2111-22.

2. Shepherd KL, James AL, Musk AW, Hunter ML, Hillman DR, Eastwood PR. Gastro-oesophageal reflux symptoms are related to the presence and severity of obstructive sleep apnoea. J Sleep Res. 2011;20:241-9.

3. Moki F, Kusano M, Mizuide M, Shimoyama Y, Kawamura O, Takagi H, et al. Association between reflux oesophagitis and features of the metabolic syndrome in Japan. Aliment Pharmacol Ther. 2007;26(7):1069-75.

4. Fujiwara Y, Arakawa T. Epidemiology and clinical characteristics of GERD in the Japanese population. J Gastroenterol. 2009;44(6):518-34.

5. Ayazi S, Tamhankar A, DeMeester SR, Zehetner J, Wu C, Lipham JC, et al. The impact of gastric distension on the lower esophageal sphincter and its exposure to acid gastric juice. Ann Surg. 2010;252(1):57-62.

6. Gregersen H, Pedersen J, Drewes AM. Deterioration of muscle function in the human esophagus with age. Dig Dis Sci. 2008;53(12):3065-70.

7. Huang CC, Chan WL, Luo JC, Chen YC, Chen TJ, Chung CM, et al. Gastroesophageal reflux disease and atrial fibrillation: a nationwide population-based study. PLoS One. 2012;7(10):e47575.

8. Velagapudi P, Turagam MK, Leal MA, Kocheril AG. Atrial fibrillation and acid reflux disease. Clin Cardiol. 2012;35(3):180-6.

9. Roman C, Bruley des Varannes S, Muresan L, Picos A, Dumitrascu DL. Atrial fibrillation in patients with gastroesophageal reflux disease: a comprehensive review. World J Gastroenterol. 2014;20(28):9592-9.

10. Kunz JS, Hemann B, Edwin Atwood J, Jackson J, Wu T, Hamm C. Is there a link between gastroesophageal reflux disease and atrial fibrillation? Clin Cardiol. 2009;32(10):584-7.

11. Kannel WB, Wolf PA, Benjamin EJ, Levy D. Prevalence, incidence, prognosis, and predisposing conditions for atrial fibrillation: population-based estimates. Am J Cardiol. 1998;82(8A):2N-9.

12. Kanagala R, Murali NS, Friedman PA, Ammash NM, Gersh BJ, Ballman KV, et al. Obstructive sleep apnea 
and the recurrence of atrial fibrillation. Circulation. 2003;107(20):2589-94.

13. Watanabe H, Tanabe N, Watanabe T, Darbar D, Roden DM, Sasaki S, et al. Metabolic syndrome and risk of development of atrial fibrillation: the Niigata preventive medicine study. Circulation. 2008;117(10):1255-60.

14. Shimazu H, Nakaji G, Fukata M, Odashiro $K$, Maruyama T, Akashi K, Fukuoka F-Scale Trial Group. Relationship between atrial fibrillation and gastroesophageal reflux disease: a multicenter questionnaire survey. Cardiology. 2011;119(4):217-23.

15. Kubota S, Nakaji G, Shimazu H, Odashiro K, Maruyama T, Akashi K. Further assessment of atrial fibrillation as a risk factor for gastroesophageal reflux disease: a multicenter questionnaire survey. Intern Med. 2013;52(21):2401-7.

16. European Heart Rhythm Association; European Association for Cardio-Thoracic Surgery, Camm AJ, Kirchhof P, Lip GY, Schotten U, Savelieva I, et al. Guidelines for the management of atrial fibrillation: the Task Force for the Management of Atrial Fibrillation of the European Society of Cardiology (ESC). Europace. 2010;12(10):1360-420.

17. Kusano M, Shimoyama Y, Sugimoto S, Kawamura O, Maeda M, Minashi K, et al. Development and evaluation of FSSG: frequency scale for the symptoms of GERD. J Gastroenterol. 2004;39(9):888-91.

18. Tsuneda T, Yamashita T, Fukunami M, Kumagai K, Niwano S, Okumura K, et al. Rate control and quality of life in patients with permanent atrial fibrillation: the quality of life and Atrial Fibrillation (QOLAF) study. Circ J. 2006;70(8):965-70

19. Yamamoto M, Watanabe E, Suzuki T, Yamazaki T, Ohtsu H, Ozaki Y, et al. Association between the quality of life and asymptomatic episodes of paroxysmal atrial fibrillation in the J-RHYTHM II study. J Cardiol. 2014;64(1):64-9.

20. Zhang JX, Ji MY, Song J, Lei HB, Qiu S, Wang J, et al. Proton pump inhibitor for non-erosive reflux disease: a meta-analysis. World J Gastroenterol. 2013;19(45):8408-19.

21. Boeckxstaens G, El-Serag HB, Smout AJ, Kahrilas PJ. Symptomatic reflux disease: the present, the past and the future. Gut. 2014;63(7):1185-93.

22. Bunch TJ, Packer DL, Jahangir A, Locke GR, Talley NJ, Gersh BJ, et al. Long-term risk of atrial fibrillation with symptomatic gastroesophageal reflux disease and esophagitis. Am J Cardiol. 2008;102(9):1207-11.

23. Lin K, Chen X, Zhang L, Wang Y, Shan Z. Proton pump inhibitors as also inhibitors of atrial fibrillation. Eur $\mathrm{J}$ Pharmacol. 2013;718(1-3):435-40.

24. Nakamura H, Nakaji G, Shimazu H, Yasuda S, Odashiro K, Maruyama $\mathrm{T}$, et al. Case of paroxysmal atrial fibrillation improved after the administration of proton pump inhibitor for associated reflux esophagitis. Fukuoka Igaku Zasshi. 2007;98(6):270-6.

25. Weigl M, Gschwantler M, Gatterer E, Finsterer J, Stöllberger C. Reflux esophagitis in the pathogenesis of paroxysmal atrial fibrillation: results of a pilot study. South Med J. 2003;96(11):1128-32.

26. Gerson LB, Friday K, Triadafilopoulos G. Potential relationship between gastroesophageal reflux disease and atrial arrhythmias. J Clin Gastroenterol. 2006;40(9):828-32.

27. DeCicco AE, Finkel JB, Greenspon AJ, Frisch DR. Clinical significance of atrial fibrillation detected by cardiac implantable electronic devices. Heart Rhythm. 2014;11(4):719-24.

28. Marcus GM, Smith LM, Scheinman MM, Badhwar N, Lee RJ, Tseng $\mathrm{ZH}$, et al. Proton pump inhibitors are associated with focal arrhythmias. J Innov Card Rhythms Manage. 2010;1:85-9.

29. Hoorn EJ, van der Hoek J, de Man RA, Kuipers EJ, Bolwerk C, Zietse R. A case series of proton pump inhibitorinduced hypomagnesemia. Am J Kidney Dis. 2010;56:112-6.

30. Cuomo R, De Giorgi F, Adinolfi L, Sarnelli G, Loffredo F, Efficie E, et al. Oesophageal acid exposure and altered neurocardiac function in patients with GERD and idiopathic cardiac dysrhythmias. Aliment Pharmacol Ther. 2006;24:361-70.

Cite this article as: Odashiro K, Yasuda S, Yokoyama T, Yoda S, Noda H, Fukata M, Arita T, Maruyama T, Akashi K. Prevalence of gastroesophageal reflux disorder in arrhythmic patients and adjunctive effects of proton pump inhibitors on comorbid atrial fibrillation. Int J Basic Clin Pharmacol 2015;4:644-50. 